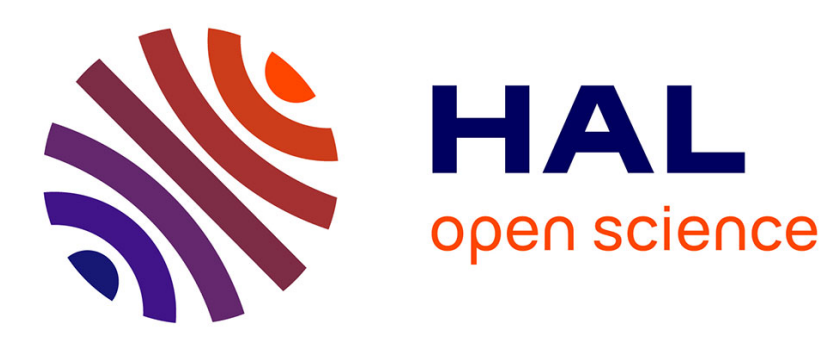

\title{
Beyond Solidarity and Accumulation Networks in Urban Informal African Economies
}

Jean-Philippe Berrou, François Combarnous

\section{To cite this version:}

Jean-Philippe Berrou, François Combarnous. Beyond Solidarity and Accumulation Networks in Urban Informal African Economies. European Journal of Development Research, 2018, 30 (4), pp.652-675. 10.1057/s41287-017-0093-4 . halshs-02280369

\section{HAL Id: halshs-02280369 \\ https://shs.hal.science/halshs-02280369}

Submitted on 6 Sep 2019

HAL is a multi-disciplinary open access archive for the deposit and dissemination of scientific research documents, whether they are published or not. The documents may come from teaching and research institutions in France or abroad, or from public or private research centers.
L'archive ouverte pluridisciplinaire HAL, est destinée au dépôt et à la diffusion de documents scientifiques de niveau recherche, publiés ou non, émanant des établissements d'enseignement et de recherche français ou étrangers, des laboratoires publics ou privés. 


\title{
Beyond Solidarity and Accumulation Networks in Urban Informal African Economies
}

\author{
Jean-Philippe Berrou \\ LAM - UMR CNRS 5115 \\ Sciences Po Bordeaux \\ 11 allée Ausone \\ F-33608 Pessac Cedex \\ $\&$

\section{François Combarnous} \\ GREThA - UMR CNRS 5113 \\ University of Bordeaux \\ Avenue Léon Duguit \\ F-33608 Pessac Cedex
}

\begin{abstract}
This paper examines the role and nature of entrepreneurs' social networks in the urban informal economy of Bobo-Dioulasso (Burkina Faso). Using an original dataset, the configuration of social networks is described based on three salient dimensions: tie content, member attributes and network structure. Multidimensional analysis allows for the simultaneous consideration of all three dimensions. Our findings suggest that network configurations at play extend well beyond the standard distinction between solidarity and accumulation networks. The complex networks highlighted by this study are consistent with rapid social changes in contemporary urban Africa. They can also significantly enhance the outcomes of small businesses.
\end{abstract}

Keywords: Informal economy; Social networks analysis; Micro and Small Enterprises; Sub-Saharan Africa; Burkina Faso 


\section{Introduction}

The African continent has been experiencing rapid economic and social changes for 15 years. With an annual average economic growth of more than $5 \%$ over this period, the continent has raised many hopes for its emergence. However, the recent slowdown highlights the persistence of significant structural vulnerabilities in many of these economies. With a small number of jobs created in the so-called "modern" sectors, the informal economy still has considerable weight, representing between 60 and $70 \%$ of non-agricultural employment and between 25 and 50\% of GDP (Benjamin and Mbaye, 2012; La Porta and Shleifer, 2014, Vanek et al., 2014).

Understanding the informal economy, the socio-economic dynamics of micro and small enterprises (MSEs) and the constraints they are facing is therefore of utmost importance from a political, economic and social point of view (De Vreyer and Roubaud, 2013). Among the constraints considered, social constraints are of particular importance in Sub-Saharan Africa (SSA), and may result from social networks. In the current framework of states and institutional failure in SSA, social networks and personal relations inevitably play an important part in structuring economic activities, particularly for micro and small enterprises in informal economies. They may impose "forced solidarity" and redistributive pressure, while also facilitating access to a range of useful resources for entrepreneurs, such as information, ideas and knowledge (about markets, activities, and skills), or financial and material support (especially in times of crisis) (Berrou and Combarnous, 2012; Grimm et al., 2013; Khayesi et al., 2014; Nordman and Doumer, 2015). This last aspect is of particular significance in the case of MSEs, since it tends to compensate for the limited internal resources of small firms.

There are two interrelated perspectives in research on contemporary social networks in African urban informal economies and MSEs (Barr, 2002). The first relates to the analysis of inter-firm networks in industrial sectors or clusters in developing countries (Meagher, 2010). The second derives from social capital literature and focuses on entrepreneurs' social networks. It attempts 
to evaluate their nature, role and impact on entrepreneurial success and economic performance (Barr, 2002; Fafchamps and Minten, 2002; Grimm et al., 2013).

This paper adopts the latter perspective, according to which entrepreneurs' networks are defined as a set of regular social relations with other agents who convey essential resources for the current exploitation of their activity (Hoang and Antoncic, 2003). These social relations impact the start-up and/or current dynamics of small businesses by facilitating or constraining access to critical resources (whether tangible or intangible). Although these resources are considered crucial for business exploitation, it is important to note that this does not say anything about the quality, reliability or effectiveness with which they are conveyed through relationships. The key factor is the intrinsic nature of these relations in terms of tie content, member characteristics and, in short, network configuration. Three salient dimensions are thus often used to describe the configuration of a social network (Crossley et al., 2015): (i) tie content (strength, social role - family, friendship, etc. -, exchanged resources), (ii) members' attributes (sociodemographic and social status, professional occupation) and network structure (size, density). Each dimension has been the subject of much discussion and theorizing in literature in developed countries (mostly in sociology and economics), notably in relation to their impact on the diffusion of resources and consequently on economic outcomes. The three dimensions have thus often been studied separately.

In the economic literature on social networks in developing countries, most studies focus on the size of networks (the number of regular contacts that an agent has with other categories of agents) (Nordman and Pasquier-Doumer, 2015). Few studies have attempted to investigate the specific effect of different dimensions of these networks, nor how they interconnect and produce specific configurations of entrepreneurs' networks that may differently impact economic performance. In the literature on African MSEs and informal economies, it is often assumed that there are two main types of networks. "Solidarity" or "survival" networks are 
often opposed to "innovative” or "accumulation” networks (Barr, 2002; Meagher, 2010). While solidarity networks tend to be small, dense, homogeneous and with poorly resourced personal relations, accumulation networks are wide, geographically dispersed and far more diversified in terms of member status (ties with privileged social classes). This standard typology is based on an a priori distinction or classification that has yet to be confirmed by ex post statistical evidence. More importantly, it is based on the implicit theoretical assumption that weak ties promote access to high social status members and thus contribute to large sparse networks (and conversely, strong ties). However, new forms of sociability are emerging in urban Africa in a context of rapid social change, under the pressure of urbanization and economic change. These new forms of sociability tend to be more selective (even instrumental) and more affinity-based, and are generally more contractual (Lourenço-Lindell, 2002; Meagher, 2010). Therefore, it would appear that more complex social networks than those usually described may be at work in urban informal African economies.

Our paper aims to disentangle the nature and role of entrepreneurs' networks of support in economic performances of informal MSE in an urban African area. To do so, we have sought to overcome some of the limitations of previous studies on social networks and informal enterprises in Sub-Saharan Africa. Firstly, we have used a unique dataset collected for an original survey conducted on a representative sample of 317 entrepreneurs between February and July 2007 in the informal economy of Bobo-Dioulasso (Burkina Faso). In addition to sociodemographic and economic data, specific data relating to personal networks was also collected from a subsample of 278 entrepreneurs. The name generators used to collect personal network data are based on criteria of the resources exchanged that make it possible to avoid pre-defining the social boundaries of the networks (see the usual distinction between family networks or business networks, for example). Secondly, this paper is the last stage of a three-stage research agenda. Two previous research projects focused on the specific effects of two isolated 
dimensions: the content of ties (Berrou and Combarnous, 2012)and network members' (alters) attributes (Berrou and Combarnous, 2011). In this paper, we go beyond this previous research in at least two ways: we include the third dimension of network structure, while maintaining a fairly fine description of the first two dimensions; and, more importantly, we simultaneously consider the three dimensions to identify how they produce specific configurations of networks and to test their differentiated impacts on MSEs economic outcomes.

The remainder of the paper is organized as follows. Section 2 reviews the mechanisms by which the three dimensions of entrepreneurs' personal networks influence the economic performance of African MSEs. The interconnectedness of the three dimensions is also discussed. The data, the survey methodology (particularly the multiple name generator instrument for personal network data) and measurement options are discussed in Section 3. After a brief description of the sample, section 4 provides an innovative ex post typology of entrepreneurs' social networks. The potential effects of the different configurations of networks on the outcomes of informal entrepreneurs are assessed in Section 5, and the results are discussed. Finally, some concluding remarks are made in Section 6.

\section{From tie strength to network structure: the configuration of entrepreneurs' personal networks in African MSEs}

The mechanisms by which the personal network influences the economic outcomes of MSEs can be analyzed through three dimensions: tie content, alters' (or member) attributes and network structure (figure 1). Each of these dimensions has been theorized and empirically investigated in existing literature. However, the way in which the three dimensions can be linked together in specific network configurations has seldom been examined.

\subsection{The three dimensions of social networks and their economic impact on African MSEs}


Since Granovetter's pioneering theory on "the strength of weak ties" (1973), the effect of tie strength on economic performance has clearly emerged as one of the most studied issues relating to the impact of tie content. ${ }^{1}$ This question is known in social capital literature as the "bonding" vs. "bridging" social capital debate (Woolcock, 2001). The importance of weak ties lies in their bridge function. In a given network, a bridge is a tie that provides the only path between two individuals or groups of individuals. The central hypothesis put forward by Granovetter (1973) is that strong ties create closed networks, whereas weak ties enable access to social circles beyond actors' direct networks. In this sense, weak ties play a crucial role in providing access to useful information. This argument is premised on the structural role of weak ties (that is, bridges in the network). However, Granovetter also recognizes the inherent value of social ties by highlighting the "strength of strong ties", in particular because of their accessibility for poor and vulnerable people (Granovetter, 1983). In other words, strong ties are more accessible and may ensure higher quality in the transmission of resources. Therefore, the effect of tie strength on economic activities is not univocal and may be contingent on the social context or the type of resource exchanged (Granovetter, 1983). The analysis of the economic effects of tie strength reveals what Uzzi (1997) calls the "paradox of embeddedness", involving an emphasis on the importance of a mix of strong and weak ties. These results have been confirmed by the empirical literature on MSEs in sub-Saharan Africa. Focusing on agricultural traders in Madagascar, Fafchamps and Minten (2002) noted that weak ties, such as non-kin relationships, are vital for accessing and sharing market information. The authors also emphasized the importance of strong ties for risk-sharing or social insurance, but also for market relations with suppliers and customers (regular relations ensure secure supply and demand, reduce transaction costs and favour credit or delayed payment). The role of family networks for informal entrepreneurs in Ouagadougou is also stressed by Pasquier-Doumer (2013), as is their safety-net function in the Ouagadougou labor market (Nordman and Pasquier 
Doumer, 2015). However, evidence of the redistributive pressure associated with strong ties, particularly kinship ties (forced solidarity), is also growing (Baland, Guirkinger and Mali, 2007; Di Falco and Bulte, 2011; Grimm et al., 2013; Khayesi et al., 2014). In such cases, family and kinship ties can become an important obstacle to the development of MSEs. We showed in a recent study (Berrou and Combarnous, 2012) that, in the case of informal MSEs in BoboDioulasso (Burkina Faso), successful small urban informal entrepreneurs draw on both embedded social relations (strong ties) and more autonomous relations (business ties). In a recent experiment in Ghana, Fachamps et al. (2014), found that internal pressure (self-control) has a greater effect on the efficient use of capital than external pressure (redistributive pressure).

For the most part, alters' attributes have been studied from the standpoint of social resources theory, or social capital theory, developed by Nan Lin (2001). Taking a hierarchical view of social structures, Lin argued that the success of an action depends on two factors: the presence of high social status contacts in the personal network, enabling access to relevant and better quality resources, and the status diversity of the network, which increases the probability of accessing appropriate resources for any issue. In economic literature, this approach refers to the notion of "linking social capital" (Woolcock, 2001), which describes the ties that connect individuals to people or groups in positions of political and financial power. The adaptation of this theory to an African informal economy has rarely been an object of empirical analysis and assessment. Using the same data on informal MSEs in Bobo-Dioulasso (Burkina Faso), we found that relations with intermediate status members are more valuable than relations with higher status members for access to both business and social resources (Berrou and Combarnous, 2011). One explanation involves contract flexibility for business ties and approachability for social support. Other explanations have been offered in qualitative studies showing that relationships with the most powerful actors may lead to unequal exchange relations of domination and subordination (Lourenço-Lindell, 2002; Meagher, 2010). 
Detailed investigations of network structures are notably absent from most studies devoted to African MSEs, if it is assumed that network size (the number of contacts) is an inadequate or at least incomplete measure. Network size is often considered to be a crucial aspect of the impact of networks on MSEs (Barr, 2002; Fafchamps and Minten, 2002; Fafchamps, 2004). However, according to Burt's structural holes argument (Burt, 1992), what matters is not the number of contacts but rather "the number of non-redundant contacts": "Contacts are redundant to the extent that they lead to the same people, and so provide the same information benefits." $(1992,17)$. A structural hole is the gap between non-redundant contacts. The greater the number of structural holes in an actor's network, the greater the returns in terms of information access and control (position of "tertius gaudens"). However, Burt's argument requires further analysis since it contrasts sharply with other approaches to network structures. Coleman (1988), and to some extent Granovetter (1985), argued that dense and cohesive networks enable the emergence of collective norms and therefore have a significant impact on the actors' behaviour. Social control and pressure may limit treachery and favor trust and cooperation. The fear of being excluded from a business community is the core determinant of the reputation mechanism of contract enforcement in African markets (Fafchamps, 2004). This mechanism depends on the reliability of the information transmitted about individuals' past behaviour. A network with many structural holes can affect the quality of the information transmitted along chains of relations.

\subsection{Solidarity versus accumulation networks}

The different results for each network dimension are also found in standard typologies developed in the literature, notably in Barr's study (2002) of the Ghanaian manufacturing sector and in Meagher's analysis of Nigerian clusters (2010). Both make a distinction between what 
they respectively call "solidarity" and "survival" networks and "innovative" and "accumulation" networks. Survival networks tend to be small, dense, locally concentrated and with strong ties and poorly resourced personal relations (with no access to advantageous economic positions or privileged commercial groups). These types of networks tend to be very homogeneous in terms of member attributes. Though they reduce risks and income variability, they have little impact on economic performance and tend to undermine rather than enhance profits (Barr, 2002). Conversely, accumulation networks are large, geographically dispersed and far more diversified in terms of member status. They consist of advantageous ties with privileged access to resources (ties with privileged social classes, civil associations and successful traders, especially international traders). These types of networks are assumed to be more profitable for MSEs. The definition or identification of standard network configurations as described above addresses the important question of how the three network dimensions are interlinked and with what effects for MSEs. The economic impact of each network dimension may be conditioned on how they fit together in specific network configurations. One network dimension may have no economic impact in itself, but will have an impact when combined with other dimensions of the network. Standard typologies have failed to provide a convincing answer to the complementarity issue. The issue is invariably constructed a priori and relies on an implicit link between the three network dimensions: weak ties promote access to alters with high social status that are often non-redundant, thus promoting the formation of personal networks rich in structural holes. Thus, what is empirically observed is how the characteristics of entrepreneurs' networks are more or less similar to those of innovative or solidarity networks (Barr, 2002). The validity of this typology has not been empirically tested, and nor has the link between weak ties and high social status alters. In a context of increasing social changes in urban areas of Africa (Meagher, 2010), the stability of the typology is made all the more questionable. We 
propose to overcome these shortcomings by developing and implementing an a posteriori approach based on specific network data.

\section{Data source and method}

\subsection{Data}

The data was collected in 2007 in the informal economy of Bobo-Dioulasso in Burkina Faso, one of the poorest countries in the world. In 2007, GNI per capita was estimated at US\$430 (World Bank, 2009). Almost half the population is thought to live below the poverty line. The importance of the informal economy in Burkina Faso reflects regional tendencies, and up to 70\% of employment (Benjamin and Mbaye, 2012; De Vreyer and Roubaud, 2013). At the time of the survey, Bobo-Dioulasso was the second largest city in the country and is still the second largest city, with a rapidly growing population. In a context of decentralization, BoboDioulasso's situation is quite specific, both driven by a strong historical commercial heritage, and economic decline since the 1970s (Fauré and Labazée, 2002). Bobo-Dioulasso's local economy shows a strong dualism between a major informal sector (particularly in trade activities), which constitutes $50 \%$ of local wealth, and modern industrial activities providing just under a third of local wealth (Growth Local Product - GLP) (Fauré and Labazée, 2002). The service sector represents $57 \%$ of GLP, against $41 \%$ for the secondary sector. The bulk of the city's employment comes from the informal economy, which ensures $68.2 \%$, against only $16.2 \%$ for the modern economy, and $15.6 \%$ for the primary sector.

Between February and July 2007, a survey was conducted on a representative sample of 317 entrepreneurs. First, sociodemographic and economic data was collected, focusing in particular on features, types of activity, employment, economic capital and outcomes. Secondly, the statistical information was completed few weeks later by collecting personal network data on a 
subsample of 278 entrepreneurs. ${ }^{2}$ The boundaries of the informal economy were empirically defined using ILO criteria (scale of activity and official registration) (ILO, 1993), plus accounting criteria. The sample is distributed by economic sector (production, retail trade and services) and sub-sectors, and by geographical area, based on the results of the last comprehensive census of economic activity in Bobo-Dioulasso (Fauré and Labazée, 2002). Of the sample, fourteen entrepreneurs participated in an in-depth interview in 2008. The qualitative material will be used to illuminate the discussion of the results.

\subsection{The ego-centered network data and the multiple name generator instrument}

An "ego-centered" (or "personal") network is defined as an actor's network of relations with others. A network of this kind is composed of a focal actor (known as the ego), the ego's network of direct social contacts (named alters) and the ties between them (see Figures 1 and 2) (Wellman, 2007). There are different instruments for data collection on personal or egocentered networks (Crossley et al., 2015). The name generator method is the most commonly used approach in the field of entrepreneurship in industrialized countries (Hoang and Antoncic, 2003; Slotte-Kock and Coviello, 2010), although it has seldom been used in sub-Saharan Africa. Name generators consist of one or several questions designed to invite respondents (i.e. egos) to recall and elicit people (alters) with whom they maintain certain types of direct relationships. They are usually followed by questions called "name interpreters" that are designed to gather information on alters' attributes, the relationships between the ego and alters, and the relationships between alters. The name generator method has been used in studies of social support networks among women in rural Africa, and has been shown to be relatively reliable, particularly in its capacity to highlight the core of personal networks (Adams, Madhavan and Simon, 2006). 
In this study, the instrument was constructed following several tests to take into account different biases identified in literature (such as memory and cognitive biases). The instrument is based on multiple name generators (Fischer, 1982). Eight name generators were used. These were defined on the basis of a criterion of interdependency or regular interaction among individuals involved in social relations conveying resources needed for the current exploitation of their informal activity (during the last twelve months). ${ }^{3}$ Seven types of exchanges or resources were used to construct the first seven generators: (i) advice, information and ideas (concerning markets, management, investment and partners); (ii) support in administrative or bureaucratic relationships (with local institutions, for example in order to secure favourable conditions on tax payments, point of sale location or conflict resolution); (iii) regular suppliers; (iv) loyal customers; (v) cooperation or partnership (entrepreneurs who support each other, in some cases pooling resources, contacts and clientele); (vi) financial backing (support in times of crisis or as part of an investment through loans or gifts); and (vii) recruitment contacts (access to employment). Lastly, a "contextual name generator" was also included. The "contextual name generator" instrument refers to important support relations at the moment of starting up a business, which are invariably active in entrepreneurs' networks. To limit the duration of the interviews, the number of alters cited for each generator was restricted to three (two for the second generator). ${ }^{4}$ Furthermore, in addition to the eight generators, a final name-eliciting question was added for additional important contacts that might have been forgotten. Once the full name list had been elicited (1964 names; an average network size of 7.06 names per entrepreneur), the respondents were asked to characterize each relation from a social-role perspective (kin, friend, neighbour, business tie, acquaintance). For a representative subsample of relations (1324), complementary name interpreters focused on tie content (duration, contact frequency, trust intensity, context of creation), alters' attributes (age, gender, ethnicity, education, occupation, status), and ties between alters..$^{5}$ Regarding occupation, respondents 
were asked to provide detailed descriptions of alters' occupations and their sector of activity. The information was then ranked using classifications of occupations and social status. For the social status classification, the level of education and other proxies of alters' wealth were used, including means of transport (vehicle, moped, cycle) and residential status (owner, tenant, family yard resident). Data on ties between alters were collected through matrices crossreferencing elicited names. By only focusing on whether alters know each other or not, the likelihood of an emotional or perception bias concerning this question was thus reduced. As an example taken from our database, Figure 2 illustrates the rich data provided by the name generator instrument for the purposes of describing entrepreneurs' personal networks in terms of their three dimensions.

\subsection{Measuring dimensions of ego-centered networks}

The data collected during our survey can be divided into two datasets. The "entrepreneurs dataset" $(n=317)$ is composed of variables concerning entrepreneurs' features and economic activities. The "ties dataset" $(n=1324)$ relates to the subsample data collected through name generators and interpreters. The data provides individual profiles of respondents' personal network members, which can be aggregated into measures of an entrepreneur's network configuration according to its three dimensions (tie content, alters' attributes, network structure).

The content of social relations composing entrepreneurs' personal networks can be divided into three salient dimensions: social role, resource content and strength. In the case of the first two dimensions, the proportion of professional ties in networks and the proportion of tangible resources among conveyed resources were considered. ${ }^{6}$ More importantly, tie strength needs to be examined. As the issue is clearly multidimensional, we need to compute a quantitative measure inferred from variables collected specifically for this purpose: tie contact frequency, 
duration, trust intensity (or closeness) and reciprocity (or mutual aid). To do so, multiple correspondence analysis (MCA) was used to compute a succession of quantitative variables summarizing the four initial categorical variables. The first principal component generated by MCA captures almost $75 \%$ of initial variables inertia, and thus offers a trustworthy weighted combination that can be used as a quantitative indicator of tie strength.

Our analysis of alters' attributes in entrepreneurs' personal networks focuses on three different aspects. The first is social status. Focusing on ego, we distinguish alters with an intermediate status (business owners at the upper end of the informal sector, small and medium-sized formal enterprise owners, and workers and unqualified employees in the formal private and public sectors) and alters with a higher status (executives, managers and officers in the formal private and public sectors, intellectual and intermediate occupations in the formal private and public sectors). ${ }^{7}$ To avoid a restrictive view of alters' attributes, we also considered the sociodemographic similarity between an ego and his or her alters (homophily, or its reverse, heterophily). Similarity is assessed using four socio-demographic characteristics (age, ethnicity, religion and geographical location), thus providing an indication of the sociodemographic openness of entrepreneurs' networks. ${ }^{8}$ The last aspect concerns the professional occupations of a network's members, which can be assessed based on the diversity of alters' occupations, measured by the ratio between the number of distinct occupations among an ego's relations and the total number of ties in its network. Lastly, concerning the openness of an ego's relations to occupations other than his or her own, we considered the proportion of ties involving alters belonging to the same profession as the ego.

Network structure and the idea of structural holes can be measured in different ways. A first simple measure is provided by network density (number of existing ties between alters divided by the total number of potential ties). A more in-depth approach is provided by Burt's wellknown measure of "structural constraint", which simultaneously expresses both the size and the 
density of a personal network. It measures the extent to which the overall relational investment of the ego directly or indirectly implies a similar alter. It is computed as the sum of structural constraints exerted by each alter, which depend on an ego's relational investment and alters' relations. ${ }^{9}$ Measurements of the structural constraint for each respondent were calculated using UCINET VI (Borgatti, Everett and Freeman, 2002). The results range from zero for wide networks of non-redundant contacts to one for limited and closely interconnected networks.

\section{A multidimensional identification/characterization of network configuration ${ }^{10}$}

In order to describe the configuration of entrepreneurs' networks, we propose a multidimensional approach that simultaneously considers the three dimensions of networks. We simultaneously consider the nine variables describing network structure, tie content and alters' attributes. A mixed classification procedure was used to identify groupings of entrepreneurs showing homogeneous network configurations. ${ }^{11}$ The analysis highlights four homogeneous clusters categorizing the different types of networks supported by entrepreneurs. Since all observations are automatically classified in such a procedure, the resulting typology may be blurred by individuals whose network profile is not clearly distinct from the average profile. To avoid this flaw, we created a fifth category that includes entrepreneurs whose network is indistinct in terms of the categories generated by cluster analysis. This additional cluster brings together entrepreneurs whose network profiles barely differ from the average profile. ${ }^{12}$ To describe the resulting typology, Table 1 shows the average values of the full range of nine classification variables for each category. Furthermore, in order to facilitate the interpretation of the results, Table 2 indicates the average values of various other relevant variables relating to the entrepreneurs and other characteristics of their networks and activities.

Network A can be described as the Urban Solidarity Network (USN). A USN is characterized by high median tie strength (.623) and includes a significant proportion of strong ties $(47.2 \%)$. 
These ties were mostly created before the start of the activity (64.7\%) and are primarily kinship and sociability ties. Conversely, the USN has the weakest proportion of business relations. The resources conveyed by this network are for the most part intangible (particularly advice, information and support in administrative relationships; see Table A.3 for details). USNs are mostly composed of social resources $(67.5 \%)$. They are also relatively rich in terms of the number of distinct resources conveyed per network (7.43). Concerning alters' hierarchical status, members tend not to be in a high social position (13.7\%). $62.9 \%$ of alters have a similar or lower status than the ego, while $23.3 \%$ have an intermediate status. Ties are also socially homophilous. This type of network is described as urban to emphasize a major difference with the usual solidarity or survival networks described by Barr (2002) and Meagher (2010). This difference is highlighted by the value of the structural constraint (.551), which is not particularly high, but relatively close to the average. A first explanation is that the USN is the largest network (7.45 members on average). A second explanation may be the likely decoupling of interpersonal relationships from their community framework in an urban context of economic pressure. The assumption is that the context favours the emergence of new forms of social solidarity that are more selective (even instrumental) and more affinity-based (one may consider, in particular, the role of sociability ties). Another explanation involves emphasizing the lack of overlap between business and family circles.

Conversely, network B is very similar to the "solidarity network" identified by Barr (2002) and Meagher (2010). Here, it will be referred to as the Community Solidarity Network (CSN) to differentiate it from the USN described above. A CSN is very small (4.15 members on average), highly constraining (.950) and poorly resourced (4.54). This type of network is based on a high proportion of kinship ties (43.9\%) and therefore has a high proportion of strong ties $(47.4 \%)$. Although it is socially homogenous (homophilic ties and same social status alters), it is less professionally cohesive (significantly different occupations among alters). Considering the 
proportion of business ties $(51.9 \%)$ and the level of structural constraint, there appears to be a significant overlap of business and family circles. Dense $C S N$ s are relatively typical of retail trade activities and small services. CSNs are also well developed among female entrepreneurs.

Network C can be termed Linking Network $(L N)$ in reference to the concept of "linking social capital" (Woolcock, 2001). In terms of composition, this type of network is close to the “innovative" or "accumulation" network defined by Barr (2002) and Meagher (2010). A linking network is characterized by a high proportion of high social status ties (almost one third). These relations are often weak (average of .327), heterophilic (socially heterogeneous) (54\%) and largely extra-professional (less than $15 \%$ of alters in the same occupation). An $L N$ is an averagesized (6.84) and relatively unconstraining network (.454) and confirms the hypothesis underlying Granovetter and Lin's “strength of weak ties" arguments and Burt's "structural holes" argument: weak ties promote access to alters with a high social position and thus imply a network with weak structural constraints. Although the proportion of kinship ties is the lowest, business ties are not significantly higher than in network $D$. LNs are common among entrepreneurs with high levels of education, particularly in services and especially catering activities. This can be explained by the fact that restaurant owners tend to have access to high social status individuals through their clientele. Finally, network D may be described as a Horizontal Business Network $(H B N)$. An $H B N$ is a medium-sized network mostly composed of business ties (66.5\%) and with very few kinship relations (23.5\%). The average tie strength is weak (.378) and the degree of structural constraint moderate (.591). This type of network is particularly cohesive and homogeneous both socially and professionally. Sociability ties mostly include acquaintances and work colleagues who rarely have a high social status (horizontal bridging ties, or arms' length ties). $71.6 \%$ of members have the same social status (or a lower status) while $25.3 \%$ have an intermediate status. Ties are significantly more homophilous. More than a half of $H B N$ members have the same occupation as the ego. Ties mainly convey 
tangible resources (70\%) and market resources, notably through business partnerships. This type of network is well represented among young entrepreneurs who have recently moved to Bobo-Dioulasso and who have very little professional experience (i.e. relatively new business activities). It may suggest that the social integration of these young entrepreneurs is primarily achieved through their business activities and their regular market-based relations. Business ties compensate for the weakness of their inherited social relations in the city. Moreover, we observe that $42 \%$ of them work in retail trade activities that also suggest a specific sectoral dynamic.

\section{The effectiveness of urban solidarity and horizontal business networks}

\subsection{Testing the impact of entrepreneurs' social networks on MSEs' economic outcomes}

A standard hierarchical multiple regression was applied to measure the power of network configuration issues to explain two of the MSEs' important outcomes: sales turnover and primary income. We investigated how well inputs, business and entrepreneurs' characteristics, but also network configurations predict informal business sales turnover and primary income. Sales turnover, expressed in FCFA, were computed on an average monthly basis over a 12 months period and adjusted for seasonal variations. Primary income was computed on a monthly basis as the difference between sales turnover and global monthly expenses, including raw materials and intermediate consumption, current charges (including wages and rents), and financial and administrative charges.

Two blocks of predictors were successively introduced into the regression. The first contains the usual predictor variables of informal earnings (capital and labour inputs, business and entrepreneurs' characteristics). With regard to these variables, the following remarks can be made. Firstly, capital input is a monetary estimate of the value of the machinery, tools, equipment and stock owned by entrepreneurs at the time of the survey. Labour input was measured by the monthly monetary value of wages paid to business employees, whatever their 
status. The effective contribution of labour to outcomes can thus be better appreciated since the usual "number of employees" variable is likely to be affected by a serious productivity bias. ${ }^{13}$ Secondly, business characteristics capture the impact of the sectoral distribution of activities on outcomes. They also consider the assumed positive impact of pluriactivity and control for the impact of a favourable economic situation on the activity. Thirdly, entrepreneurs' characteristics combine variables describing entrepreneurs' demographic characteristics (gender and ethnicity), human capital (education and experience) and entrepreneurial behaviour. This last variable is a score computed as a weighted combination of six dummy variables respectively reporting simplified bookkeeping, the fact of having a bank account, the formal administrative registration of the activity, the fact of belonging to a professional organization, technical training in entrepreneurship and demand anticipation. ${ }^{14}$ The second block of explanatory variables considers network configurations. It consists of four dummy variables reporting the entrepreneurs' membership of one or another of the four clusters described in Section 4.

Given the empirical approach used in this study, the reliability of OLS regression parameters may be undermined by a potential endogeneity bias, notably with regard to the direction of causality between entrepreneurs' social networks and their economic performance. Therefore, we tested whether our social network variables can be regarded as exogenous by using the standard econometric procedure of instrumental variables and different tests for identification and endogeneity. The first stage of the 2SLS regressions is used to select the most powerful instruments (table A.4.) We then selected 5 instruments (the strongest in regard to our four network variables): the proportion of ties created before starting the business and, among these ties, the median ties' strength, and the proportion of ties with higher-status alters; the proportion of alters in the same profession and the proportion of heterophilic ties. ${ }^{15}$ The implementation of the 2SLS regressions and the different tests for identification and endogeneity tend to confirm 
that the exogeneity of our network variables cannot be excluded. Obviously, the intrinsic limits of this method oblige us to be very cautious in interpreting our results. The linear estimation results are shown in Table 3. The assumptions of linearity, normally distributed and uncorrelated errors were checked and met for all regressions. We also obtained identically specified probit estimates of (i) the probability of being part of the upper third of primary income distribution and (ii) the probability of being poor, that is, of earning less than $60 \%$ of the median primary income. The probit estimation results are shown in Table A.5. Means and standard deviations of predicted and predictor variables are shown at Table A.6.

Basic regressions (1) and (3) significantly predict sales turnover and primary income, meeting the usual accuracy of the modelling of informal outcomes. We may note that whereas inputs and business characteristics significantly influence outcomes, the only entrepreneur characteristic with a significant positive impact is entrepreneurial behaviour. Neither demographics nor human capital show any significant impact on the outcomes of informal activities. As shown in Table 3 (see also in Table A.5 for the probit estimations), the addition of the block of network dummies significantly improves the prediction of outcomes (see estimations (2) and (4)). Therefore, it appears that entrepreneurs' network configurations may be a determining factor of informal entrepreneurial efficiency.

\subsection{Discussion}

The most important finding of this study is that it is the two original networks we identified the USN and the $H B N$ - that seem to have a significant impact on MSEs' economic outcomes, not the usual solidarity $(C S N)$ and accumulation $(L N)$ networks. This finding raises some questions. 
The USN has a significant impact on both earnings and turnover, and is useful for accessing the segment of top performers and for surpassing the limits of the poorer segments. These findings challenge established views of solidarity networks, which are often considered to reduce uncertainty while impeding performance (Barr, 2002). With the USN, we don't find evidence that the safety net function prevents the information function or entrepreneurial success (Nordman and Pasquier-Doumer, 2015). An important reason for this result is that this network does not exhibit strong structural constraints. This is an important finding with regard to the existing literature. Our findings suggest that USNs still play an important role as a risk-coping mechanism for vulnerable entrepreneurs and help to smooth out shocks and variability. As we have shown in Berrou and Combarnous (2012), one reason for the positive impact of USNs is based on Granovetter's “strength of strong ties” (Granovetter 1983; Lourenço-Lindell 2002). The stabilizing role of strong ties is well illustrated here by the life stories collected as part of this study, particularly during the business start-up period. The trust, length and regularity of contact of strong ties allow for a more efficient circulation of resources (particularly intangible and social resources as access to information and financial support). USNS are characterized by a significant proportion of administrative support ties - ties that are paradoxically less present in LNs. This may suggest that this type of service is more efficiently provided by alters of intermediate status (well represented in the USN) than by alters in high social positions (for example, bargaining with tax officers). However, the added value of the typology presented in this paper is precisely that it highlights complementarities between different network dimensions. The typology helps to go beyond a reified vision of solidarity networks that would necessarily be assimilated to kinship and community ties (based on the assumption that strong ties lead to similar status alters, and so favor closely interconnected networks). Here, the USN indicates a useful complementarity between strong ties and a moderate structural constraint. This is consistent with the rapid social changes affecting contemporary African cities 
(Lourenço-Lindell, 2002, Meagher, 2010). A USN is composed of a high proportion of sociability ties, and not only kinship ties. The mean size of the network (7.45) - the largest of the four types - may also be viewed as a consequence of urbanization. In terms of the hierarchical status of alters, we found that the USN is relatively balanced and diversified. Furthermore, there is no evidence of a conflict between the fact of maintaining strong solidarity ties and the development of business relationships, which accounts for 37.75 per cent of ties in this type of network. The moderate social constraint is of primary importance since it may highlight the decoupling of interpersonal relationships from their community framework and consequently a reduction in social pressure. The decoupling of the business circle from the community circle is a key element of its positive impact on the economic performance of MSEs. A $U S N$ is not as socially constraining as is commonly assumed in the literature devoted to solidarity networks. In other words, there is no evidence of "over-embeddedness", unlike what may occur in CSNs, which are typical of standard solidarity or survival networks. The significant overlap between business and family circles in $C S N S$ may explain why it has no significant impact on economic outcomes. In these kinds of networks, mechanisms of "forced solidarity" as shown by Grimm et al (2016) for tailors in Ouagadougou may occur. In the life stories collected as part of this study, we found evidence of this type of social constraint among members of CSNs. Such was the case of Rasmané (a second-hand clothes trader), whose business activities are entirely dependent on Kuanda, a relative from the same village and Rasmané's only supplier. Rasmané described the burden of this dependence, stressing his unsuccessful attempt to develop his business activities by bypassing his relation with Kuanda as, if he were to use a different supplier on a regular basis, Kuanda would construe it as a form of betrayal.

As for the USN, being embedded in a $H B N$ significantly appears to increase economic performance relative to an indistinct network. The fact that this type of network also helps to 
escape from the poorer group of entrepreneurs may be explained by the fact that it is well developed among vulnerable entrepreneurs. This type of network is well represented among young and relatively inexperienced entrepreneurs who have often recently moved to the city. The significance of $H B N s$ is consistent with other findings in existing literature, suggesting that while rigid business networks are advantageous in a stable economic environment, flexible business networks are better suited to more uncertain environments (Fafchamps, 2004). HBNs are relatively flexible since ties are for the most part weak. However, despite their weakness, such ties appear to provide the usual inherent benefits of business relationships in terms of reduced transaction costs (notably search and screening costs). By definition, such business ties are also regular ties as they show a high frequency of interaction. Regular contact may already be enough to reduce some transaction costs (through business habits and routines) and even access to credit suppliers (see Table 2). Therefore, the frequency of contacts, including the frequency of purchases of goods from the same supplier, can be seen as a kind of "signal" highlighting business dynamism (a regular buyer is far more likely to be reliable than a casual buyer). As the $H B N$ shows a moderate structural constraint, we cannot strictly confirm Burt's structural hole and structural autonomy arguments, nor the role of social pressure as a means of fostering effective business relationships. ${ }^{16}$ But our methodology makes it possible to go further in the comprehension of this network by revealing an important complementarity in the $H B N$ between business ties and occupational and social status. The professional homogeneity (on average more than half of all network members work in the same sector) of the $H B N$ is a key aspect, promoting mutual aid between entrepreneurs operating in the same sectors (by pooling orders, production, machinery, tools and contacts, notably clientele). Inter-firm cooperation may thus be a key determinant of firm efficiency, and has been emphasized in the literature on industrial clusters (Knorringa and van Staveren, 2006). This insight is supported by the positive and significant effect of the "professional organization membership" dummy variable in the 
model. The social homogeneity of the $H B N$ highlights the relationship between weak ties, similar or intermediate status alters and a relatively moderate structural constraint (thus challenging the usual theoretical assumptions). Business ties are all the more efficient when they are developed among similar activities in terms of size and sector.

Our results show that $L N s$ seem to have no significant impact on economic outcomes, except for sales turnover. ${ }^{17}$ Three main arguments can be proposed. As we have also explained in Berrou and Combarnous (2011), the first is the idea that, contrary to Lin's hypothesis, resources conveyed by closer status individuals may be more useful to informal entrepreneurs than those conveyed by higher social status individuals. This is, for example, the case with administrative support and access to information resources. Relationships with employees are more useful than relationships developed with managers and heads of departments, organizations and formal institutions. In many regards, the life stories collected as part of this study support this conclusion, including the relationships between MSEs and banks or microfinance institutions. Fatimata, a restaurant owner, explained how she had taken out five loans with the Caisse Populaire as a result of information on bank account management provided by four employees of the bank (secretaries and administrative officers) who were regular clients. The second argument is social proximity and approachability. Approachability is of primary importance, as, for example, when instant access to financial support is required in times of crisis. Here again, our life stories confirm that in times of crisis, entrepreneurs tend to solicit socially close alters for financial support. For example, Edmond, a tailor, commented that the first person to whom he would turn for financial support in times of difficulty was his wife (an administrative secretary in a formal private company) and not his first cousin (a relative in the same village), the director of one of the largest hydrocarbon companies in the country. What this suggests is a kind of self-restriction that leads entrepreneurs to avoid asking for help from alters who are too socially distant for fear of being unable to return the service. When the status difference 
between the two partners is significant, reciprocity tends to turn into a "patron-client" relationship. The final argument is, then, that relationships with more powerful actors may lead to unequal relations of domination and subordination (Lourenço-Lindell, 2002; Meagher, 2010). Alters with a high social status are too socially distant, which may lead to asymmetrical relations. But more importantly, the added value of our typology is to show that social networks have to be addressed by taking into account their three dimensions and their potential complementarities. Here, our findings suggest that the usual argument regarding the effect of big sized networks with weak structural constraints may be dependant on the nature and the content of ties of the network (see the $H B N$ ).

\section{Conclusion}

In the literature on entrepreneurs' social networks in developing countries and in African urban informal economies, little is known about the specific effect of the different dimension of these networks (Nordman and Pasquier-Doumer, 2015). When they do so, most studies emphasize two types of networks: solidarity or survival networks, and accumulation or innovative networks. This typology is based on the assumption that weak ties promote access to high social status members, and thus contribute to wide and sparse networks (and conversely for strong ties). Using original data on informal entrepreneurs' networks in Bobo-Dioulasso, and drawing on a three-stage research agenda (Berrou and Combarnous, 2011, Berrou and Combarnous, 2012), our study makes an analytical contribution to this debate by identifying ex post the configuration of entrepreneurs' personal networks in terms of three salient dimensions (tie content, alters' attributes and network structure). The methodology used in this study highlights complementarities between the three dimensions. These complementarities define four types of networks that offer a more detailed picture of the complexity of social networks structuring informal economies in urban Africa. The findings confirm the existence of solidarity and accumulation networks, referred to here as $C S N$ and $L N$. The study found that both networks 
had no significant impact on economic outcomes. More importantly, the typology highlights two other types of social networks referred to as $U S N$ and $H B N$. Their configuration was found to bypass the traditional assumption described above. USNs combine strong ties with limited structural constraints. They act as a form of informal social insurance and do not preclude activity development. $H B N s$ are characterized by weak, horizontal and professionally homogeneous business ties associated with limited structural constraints. They provide flexibility to micro-entrepreneurs whose local integration is often limited to their business circle. The discovery of these two new types of networks is consistent with rapid social changes in contemporary urban Africa. Interestingly, and even if our regression results have to be interpreted with caution, they seem to have a more significant impact on the economic performance of MSEs.

The identification of these different types of entrepreneurs' social networks and their potential effects as a barrier or a support in MSE development may help in the debate on the identification of "constrained gazelles" (Grimm et al., 2012; Fachamps and Woodruff, 2016). While further research is needed to improve our knowledge about the interaction between social networks and labour market segmentation in sub-Saharan Africa, our study also raises some policy implications. There is an obvious sense in which the networks identified in this study in various proportions combine both inherited (kinship) and selected (friendship and business) ties. Therefore, they cannot be easily supported, and even less created by policy measures. However, our results also show that business ties matter and are an important aspect of the impact of social networks on the economic outcomes of MSEs. Yet, not all micro-entrepreneurs necessarily have the same ability or opportunity to develop business relationships (for example, there are sectoral specificities). In this view, policy measures can be crucial. Firstly, the findings of this study are consistent with suggestions about the need to support an economic and institutional context that promotes the development of interactions between entrepreneurs, for instance, the development 
of business relationships. Policies may seek to support the development of professional organizations, associations and business communities, as well as places of exchange between entrepreneurs (such as marketplaces, trade fairs, or entrepreneurship training programs and local business competitions). As demonstrated by Fafchamps and Quinn (2016), it is possible to induce exogenous variations in business contacts that may facilitate the diffusion of business practices. In order to reinforce formal-informal linkages (Böhme and Thiele, 2014), policy interventions must promote more inclusive approaches in local economic planning (Chen, 2014). Finally, the role of the USNS also raises some policy implications. They still play a crucial role as a social safety net for informal entrepreneurs. The removal of this social pressure, notably by developing micro-insurance, or other forms of social insurance for the poor, could potentially enable small entrepreneurs to make even more productive use of their social networks (Grimm, Hartwig and Lay, 2016).

As concerns future research, our findings on the importance and the heterogeneity of entrepreneurs' networks suggest that a better knowledge of the emergence and evolution of these networks over time is needed. Moreover, in view of the rapid development of information technology communication (ICT) usage and mobile phone coverage in Africa (Aker and Fafchamps, 2014; World Bank, 2016), another area for further research is the effect of ICT on social networks and relational structures in urban African labour markets. 


\section{Tables}

Table 1. Network identification; means of classification variables by cluster*

\begin{tabular}{|c|c|c|c|c|c|c|}
\hline \multirow[b]{2}{*}{ Classification variables } & \multicolumn{6}{|c|}{ Clusters } \\
\hline & A & B & C & D & $\begin{array}{c}\text { Indistinc } \\
\mathbf{t}\end{array}$ & All \\
\hline \multicolumn{7}{|l|}{ Network's structure } \\
\hline Structural constraint & .551 & .950 & .454 & .591 & .481 & .564 \\
\hline \multicolumn{7}{|l|}{ Content of ties } \\
\hline Median strength of ties & .623 & .520 & .327 & .378 & .446 & .448 \\
\hline Proportion of professional ties & .378 & .519 & .582 & .665 & .520 & .539 \\
\hline Proportion of tangible resources & .601 & .658 & .673 & .700 & .646 & .657 \\
\hline \multicolumn{7}{|l|}{ Alters' attributes } \\
\hline $\begin{array}{l}\text { Proportion of intermediate status } \\
\text { relations }\end{array}$ & .233 & .150 & .165 & .253 & .207 & .209 \\
\hline Proportion of higher status relations & .137 & .102 & .305 & .031 & .140 & .145 \\
\hline Proportion of heterophilic ties & .171 & .189 & .540 & .178 & .243 & .272 \\
\hline Proportion of intra-profession ties & .226 & .124 & .141 & .532 & .270 & .284 \\
\hline Number of distinct occupations & .461 & .612 & .542 & .337 & .429 & .456 \\
\hline $\mathrm{N}$ & 60 & 26 & 61 & 69 & 54 & 270 \\
\hline
\end{tabular}

Notes : (*) Clusters have been identified using a mixed classification procedure - The values that significantly differ from those of other clusters (independent samples t-tests, $\mathrm{p}<0.1$ ) are in bold type in the table Entrepreneurs whose network shows no perceptible specificity have been gathered in the "indistinct" cluster; for measurement options, see section 4. 
Table 2. Network characterization; means of characterization variables by cluster ${ }^{*}$

\begin{tabular}{|c|c|c|c|c|c|c|}
\hline \multirow{2}{*}{ Characterization variables } & \multicolumn{6}{|c|}{ Clusters } \\
\hline & $\mathbf{A}$ & B & $\mathbf{C}$ & D & Ind. & All \\
\hline \multicolumn{7}{|l|}{ Network } \\
\hline Size (number of ties) & 7.45 & 4.15 & 6.90 & 6.84 & 8.70 & 7.10 \\
\hline Proportion of strong ties ${ }^{1}$ & .472 & .474 & .183 & .229 & .306 & .311 \\
\hline Proportion of ties set up prior to activity's creation & 647 & .590 & .564 & .537 & .552 & .576 \\
\hline Proportion of family ties & .407 & .439 & .161 & .235 & .269 & .283 \\
\hline Proportion of close-friendship ties & .257 & .176 & .219 & .233 & .259 & .235 \\
\hline Proportion of arm's length sociability ties ${ }^{2}$ & .235 & .208 & .334 & .324 & .306 & .292 \\
\hline Proportion of business-family ties ${ }^{3}$ & .054 & .080 & .014 & .069 & .034 & .047 \\
\hline Proportion of business-sociability ties ${ }^{3}$ & .205 & .228 & .273 & .366 & .301 & .283 \\
\hline Suppliers credit & .250 & .115 & .312 & .391 & .259 & .289 \\
\hline Total number of distinct resources & 7.43 & 4.54 & 6.64 & 7.14 & 8.39 & 7.09 \\
\hline Proportion of social resources & .675 & .606 & .583 & .578 & .626 & .613 \\
\hline Multiplexity $^{4}$ & 1.47 & 1.59 & 1.41 & 1.60 & 1.41 & 1.49 \\
\hline Network's average level of education ${ }^{5}$ & 1.70 & 1.49 & 2.19 & 1.38 & 1.74 & 1.72 \\
\hline Proportion of same or lower status relations & 629 & .747 & .531 & .716 & .654 & .645 \\
\hline \multicolumn{7}{|l|}{ Entrepreneur } \\
\hline Years of living in Bobo-Dioulasso & 26.0 & 22.7 & 23.3 & 20.8 & 26.9 & 23.9 \\
\hline Age & 37.7 & 36.3 & 35.7 & 32.9 & 35.8 & 35.5 \\
\hline Gender $^{6}$ & .167 & .308 & .197 & .087 & .130 & .159 \\
\hline Ethnic group $^{7}$ & .450 & .346 & .246 & .493 & .407 & .396 \\
\hline No education & .417 & .385 & .279 & .377 & .315 & .352 \\
\hline Secondary education or more & .167 & .385 & .410 & .188 & .241 & .263 \\
\hline Experience (years as owner of present activity) & 7.93 & 7.54 & 7.10 & 4.83 & 7.44 & 6.81 \\
\hline Entrepreneurial behaviour $^{8}$ & .470 & .420 & .520 & .290 & .440 & .430 \\
\hline \multicolumn{7}{|l|}{ Activity } \\
\hline Length of activity's existence & 9.68 & 8.92 & 7.10 & 5.49 & 7.94 & 7.61 \\
\hline Makeshift workshop ${ }^{9}$ & .317 & .385 & .262 & .333 & .204 & .293 \\
\hline Historical centre localization & .650 & .460 & .520 & .570 & .560 & .560 \\
\hline Production & .367 & .038 & .344 & .362 & .463 & .348 \\
\hline Trade & .300 & .462 & .147 & .420 & .241 & .300 \\
\hline Catering & .133 & .115 & .213 & .029 & .130 & .122 \\
\hline Other services & .200 & .385 & .295 & .188 & .167 & .230 \\
\hline $\mathbf{N}$ & 60 & 26 & 61 & 69 & 54 & 270 \\
\hline
\end{tabular}

Notes: $(*)$ The values that significantly differ from those of other clusters (independent samples t-tests, $\mathrm{p}<0.1$ ) are in bold type in the table; (1) strong ties are those whose strengh ranks them among the highest third of the distribution ; (2) includes acquaintances, labour colleagues and neighbours; (3) ties that are simultaneously qualified of business and family (or business and sociability) ties; (4) average number of resources conveyed by tie; (5) computed on the basis of a five level scale of education; (6) 1 = female, $0=$ male; (7) 1 = Mossi, $0=$ other ethnic group; (8); (9) 1 = makeshift workshop, $0=$ solid workshop. 
Table 3. Hierarchical multiple regression analysis summary for variables predicting sales turnover and primary incomes

\begin{tabular}{|c|c|c|c|c|}
\hline \multirow{2}{*}{$\begin{array}{l}\text { Outcome variables } \\
\text { Predictors }^{1} \\
\end{array}$} & \multicolumn{2}{|c|}{ log (turnover) } & \multicolumn{2}{|c|}{ log (primary income) } \\
\hline & $(1)$ & (2) & (3) & $(4)$ \\
\hline Constant & $3.200 * * *$ & $3.098 * * *$ & $3.363^{* * *}$ & $3.221 * * *$ \\
\hline \multicolumn{5}{|l|}{ Inputs } \\
\hline log (capital input) & $.096^{* *}$ & $.093 * *$ & $.076^{*}$ & $.075^{*}$ \\
\hline log (labour monthly input) & $.276^{* * *}$ & $.272^{* * *}$ & $.118^{* *}$ & $.117^{* *}$ \\
\hline \multicolumn{5}{|l|}{ Business characteristics } \\
\hline Production & $.148^{* *}$ & $.139 * *$ & .049 & 031 \\
\hline Retail trade & $.660^{* * *}$ & $.643^{* * *}$ & $.325^{* * *}$ & $.292^{* * *}$ \\
\hline Catering & $.638^{* * *}$ & $.637^{* * *}$ & $.553 * * *$ & $.554 * * *$ \\
\hline Pluriactivity & $.142 * *$ & $.129 * *$ & 122 & 106 \\
\hline Favourable economic situation ${ }^{2}$ & $.102 * *$ & $.109 * *$ & $.187^{* * *}$ & $.191^{* * *}$ \\
\hline \multicolumn{5}{|l|}{ Entrepreneur characteristics ${ }^{3}$} \\
\hline Ethnic group & .002 & .000 & .018 & .003 \\
\hline Gender & .004 & .012 & -.088 & -.078 \\
\hline Primary education or more & .011 & .016 & .041 & .049 \\
\hline Experience & .055 & .072 & $.095^{*}$ & $.116^{* *}$ \\
\hline Entrepreneurial behaviour score ${ }^{4}$ & $.012^{* * *}$ & $.014^{* * *}$ & $.014^{* * *}$ & $.017^{* * *}$ \\
\hline \multicolumn{5}{|l|}{ Network configuration ${ }^{5}$} \\
\hline Urban Solidarity Network & & $.157^{* *}$ & & $.215^{* * *}$ \\
\hline Community Solidarity Network & & .011 & & .024 \\
\hline Linking Network & & $.138^{* *}$ & & 099 \\
\hline Horizontal Business Network & & $.212 * * *$ & & $.254^{* * *}$ \\
\hline $\mathrm{N}$ & 270 & 270 & 270 & 270 \\
\hline F (sig) & $24.869 * * *$ & $20.277^{* * *}$ & $9.756 * * *$ & $8.521 * * *$ \\
\hline Adjusted $\mathrm{R}^{2}$ & .516 & .534 & .281 & .309 \\
\hline F change network (sig) & - & $3.546 * * *$ & - & $3.621 * * *$ \\
\hline Sargan test (p-value) & - & $2.461(0.292)$ & - & $1.619(0.445)$ \\
\hline Basmann test (p-value) & & $2.297(0.317)$ & & $1.506(0.471)$ \\
\hline Anderson canon. corr. test ( $p$-value) & & $3.302(0.347)$ & & $3.302(0.347)$ \\
\hline Hausman test ( $p$-value) & & $5.76(0.990)$ & & $18.22(0.311)$ \\
\hline Durbin (score) chi2 ( $p$-value) & & $3.241(0.518)$ & & $1.795(0.773)$ \\
\hline Wu-Hausman test (p-value) & & $.756(0.555)$ & & $.416(0.797)$ \\
\hline
\end{tabular}

Notes : (1) Unstandardized estimated coefficients are shown, $* * * p<.01, * * p<.05, * p<.1$, Variance Inflation Factors (VIF) have been calculated and shows that no severe multicollinearity occurs in our regressions, heteroskedacticity issues have also been controlled by White's correction implementation; (2) this dummy variable distinguishes activities that experienced a favourable economic situation during past year; (3) dummy variables respectively distinguishing Mossi, female, most educated and most experienced (more than five years in present activity) entrepreneurs; (4) this score combinates six dummy variables (simplified book keeping, bank account holding, administrative registration of activity, belonging to a professional organization, entrepreneurship technical training and demand anticipation) and is weighted by each item frequency so that a relatively rare item weighs more than a more frequent one; (5) excluded value is "indistinct network"; we simultaneously introduce the four dummies describing networks in the regressions as the separate introduction of each of them leads to similar conclusions. 


\section{Figures}

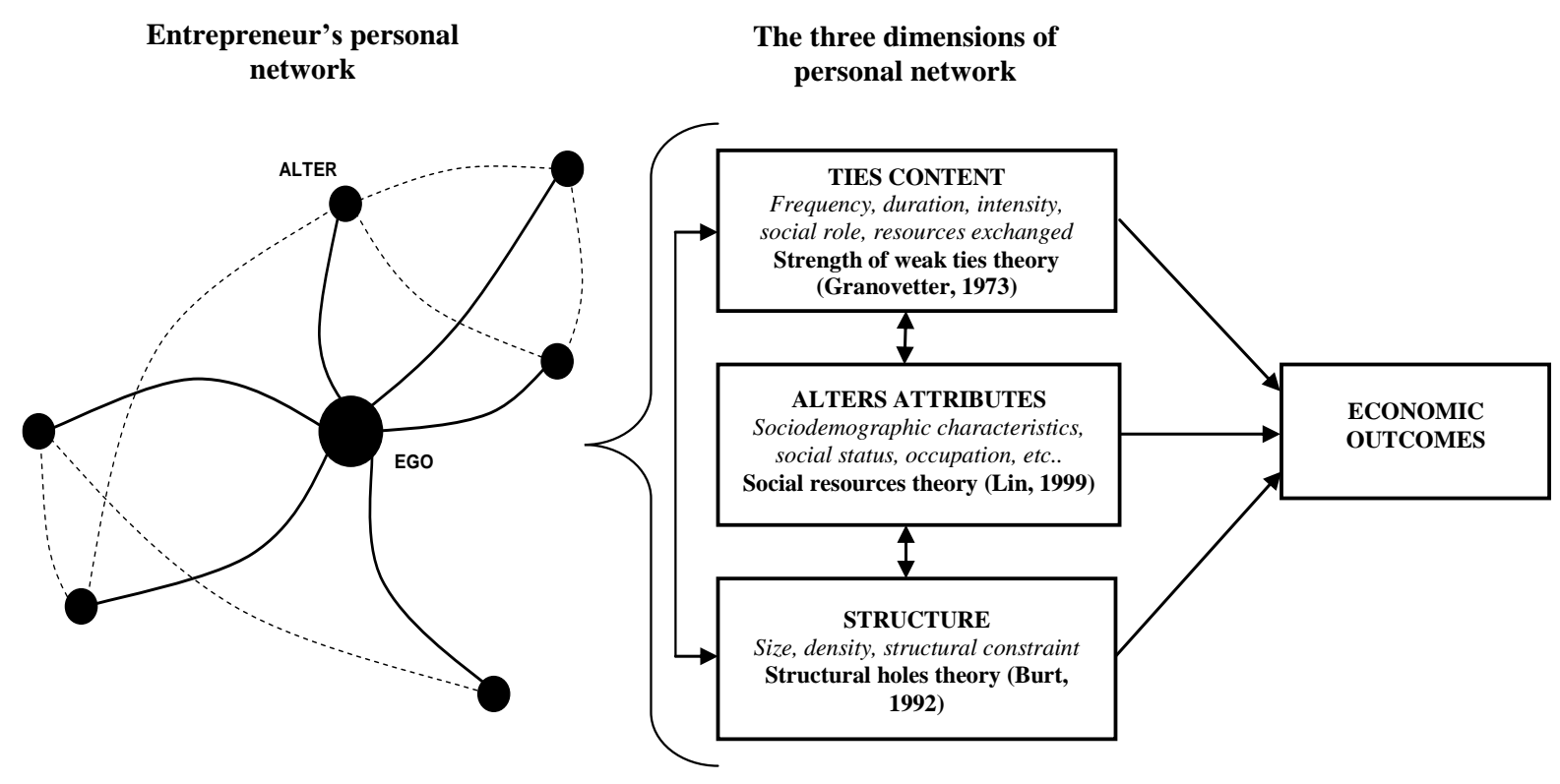

Figure 1. Configuration of entrepreneurs' personal networks and economic outcomes Source: authors. 


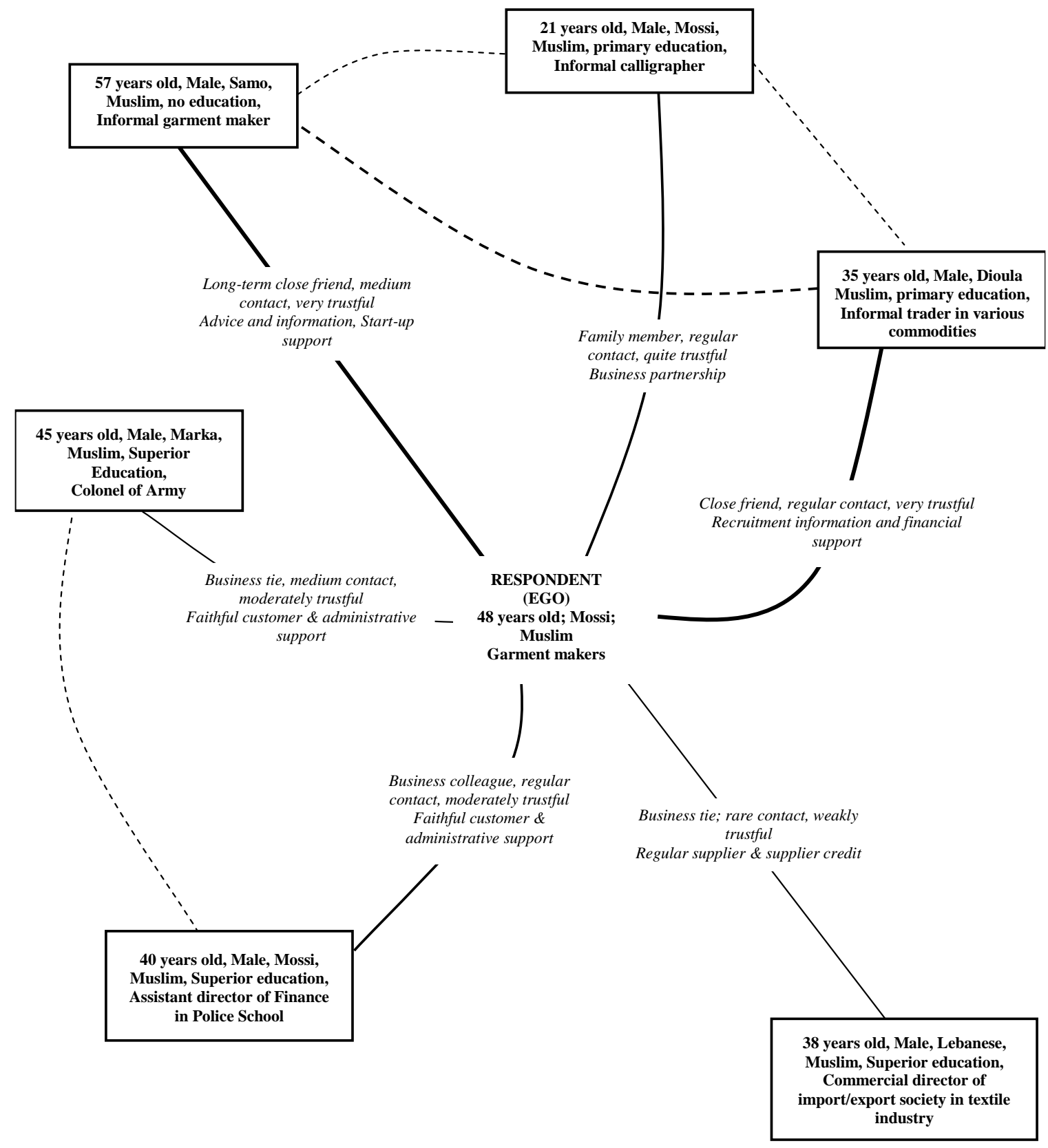

Figure 2. Informal entrepreneur's ego-centred network ${ }^{*}$

Note : (*) Ties between ego and alters are represented by continuous lines, and ties between alters by dotted lines. In both cases, line thickness depends on the intensity or strength of the tie.

Source: authors 


\section{Appendix}

Table A.1. Number of alters quoted by entrepreneurs for each names generator

\begin{tabular}{lcccc}
\hline N= 278 entrepreneurs (P= 1964 alters) & $\begin{array}{c}\text { No name } \\
(\%)\end{array}$ & $\begin{array}{c}\text { Maximum of possible } \\
\text { names (\%) }\end{array}$ & $\begin{array}{c}\text { Average names } \\
\text { quoted }\end{array}$ & Std. deviation \\
\hline Advice, information and ideas & 13.3 & 26.3 & 1.68 & 1.006 \\
Administrative support & 48.6 & 5.0 & .560 & .590 \\
Regular suppliers & 28.1 & 5.8 & .970 & .808 \\
Faithful customers & 7.6 & 39.6 & 2.08 & .930 \\
Cooperation or partnership & 30.2 & 6.5 & 1.03 & .872 \\
Financial support & 25.9 & 10.8 & 1.16 & .934 \\
Contact for recruitment & 40.3 & 5.4 & .860 & .870 \\
Start-up support & 28.8 & 4.7 & 1.03 & .836 \\
Total & & & 7.06 & 2.59 \\
\hline
\end{tabular}

Table A.2. Average principal characteristics of activities and entrepreneurs by sector. ( N=270; BoboDioulasso, 2007)

\begin{tabular}{lccccc}
\hline & \multicolumn{5}{c}{ Sectors of activities } \\
\cline { 2 - 6 } & Production & Retail Trade & Catering & Other services & Total \\
\hline Activities' Characteristics & & & & & \\
| Monthly balance of primary incomes (K FCFA) & 60 & 107 & 171 & 50 & $\mathbf{8 5}$ \\
Monthly wage bill (K FCFA) & 45 & 11 & 34 & 20 & $\mathbf{2 8}$ \\
Capital at resale price (K FCFA) & & 580 & 332 & 326 & $\mathbf{5 2 1}$ \\
Activities' duration (years) & 9.5 & 7.5 & 5.1 & 6.3 & $\mathbf{7 . 6}$ \\
Commercial registration (\%) & 7 & 21 & 0 & 10 & $\mathbf{1 1}$ \\
Entrepreneurs' Characteristics & & & & & \\
Age (years) & 37.5 & 34.2 & 37.1 & 33.4 & $\mathbf{3 5 . 5}$ \\
Household size (numbers of individuals) & 8.5 & 7.8 & 6.9 & 6.0 & $\mathbf{7 . 5}$ \\
Higher level than primary school (\%) & 14 & 23 & 42 & 34 & $\mathbf{2 6}$ \\
\hline
\end{tabular}


Table A.3. Networks exchange content; proportion of each resource by cluster*

\begin{tabular}{lcccccc}
\hline \multirow{2}{*}{ Resources } & \multicolumn{7}{c}{ Networks } \\
\cline { 2 - 7 } & USN & BNI & LN & DSN & Indistinct & All \\
\hline Advices, information and ideas & $\mathbf{0 . 2 0 4}$ & $\mathbf{0 . 2 2 7}$ & 0.160 & $\mathbf{0 . 1 5 4}$ & 0.184 & 0.180 \\
\hline Support in administrative relationship & $\mathbf{0 . 0 9 1}$ & $\mathbf{0 . 0 3 9}$ & 0.073 & 0.072 & 0.072 & 0.073 \\
\hline Regular suppliers & $\mathbf{0 . 0 8 0}$ & 0.082 & $\mathbf{0 . 1 3 5}$ & 0.119 & 0.114 & 0.109 \\
\hline Faithful customers & $\mathbf{0 . 1 3 4}$ & $\mathbf{0 . 2 2 0}$ & $\mathbf{0 . 1 9 5}$ & 0.159 & $\mathbf{0 . 1 4 1}$ & 0.164 \\
\hline Cooperation or partnership & 0.108 & 0.092 & $\mathbf{0 . 0 8 6}$ & $\mathbf{0 . 1 4 6}$ & 0.119 & 0.113 \\
\hline Financial support & 0.140 & 0.114 & 0.132 & 0.153 & 0.138 & 0.139 \\
\hline Contact for recruitment & 0.104 & 0.077 & 0.093 & $\mathbf{0 . 0 7 4}$ & 0.099 & 0.090 \\
\hline Start-up support & 0.135 & 0.149 & 0.124 & 0.124 & 0.133 & 0.131 \\
\hline
\end{tabular}

Notes: $(*)$ The values that significantly differ from those of other clusters (independent samples ttests, $p<0.1$ ) are in bold type in the table.

Table A.4. First stage of the 2SLS regression

\begin{tabular}{|c|c|c|c|c|}
\hline Outcome variables & \multirow{2}{*}{ USN } & \multirow{2}{*}{ CSN } & \multirow{2}{*}{ LN } & \multirow{2}{*}{ HBN } \\
\hline Predictors $^{1}$ & & & & \\
\hline Constant & .578 & .242 & .151 & $.522^{* *}$ \\
\hline \multicolumn{5}{|l|}{ Instrumental Variables } \\
\hline $\begin{array}{l}\text { Proportion of ties created before starting } \\
\text { the business }\end{array}$ & $.283 * * *$ & .007 & -.045 & $-.216^{* *}$ \\
\hline $\begin{array}{l}\text { Median strength of ties created before } \\
\text { starting the business }\end{array}$ & $.002^{* *}$ & $.002 * * *$ & $-.005^{* * *}$ & -.002 \\
\hline $\begin{array}{l}\text { Proportion of ties created before starting } \\
\text { the business with higher-status }\end{array}$ & .018 & $-.243 * * *$ & $.331 * * *$ & -.174 \\
\hline $\begin{array}{l}\text { Proportion of ties created before starting } \\
\text { the business that are heterophilic }\end{array}$ & $-.291 * * *$ & -.023 & $.450 * * *$ & -.070 \\
\hline $\begin{array}{l}\text { Proportion of ties created before starting } \\
\text { the business in the same profession }\end{array}$ & $-.227 * * *$ & $-.150 * *$ & -.070 & $.547 * * *$ \\
\hline
\end{tabular}

\section{Control Variables}

log (capital input); log (labour monthly input); Production; Retail trade; Catering; Pluriactivity; Favourable economic situation; Ethnic group. Gender; Primary education or more; Experience ;

\begin{tabular}{l|c|c|c|c}
\hline $\mathrm{N}$ & 270 & 270 & 270 & 270 \\
$\mathrm{~F}($ sig) & $2.07 * * *$ & $3.09 * * *$ & $6.25^{* * *}$ & $6.23^{* * *}$ \\
\hline Adjusted $\mathrm{R}^{2}$ & .063 & .117 & .249 & .379 \\
\hline
\end{tabular}

Notes : (1) Unstandardized estimated coefficients are shown, $* * * p<.01, * * p<.05, * p<.1$, 
Table A.5. Probit estimations for variables predicting survival entrepreneurship and entrepreneurial success

\begin{tabular}{|c|c|c|c|c|}
\hline \multirow{2}{*}{$\begin{array}{l}\text { Outcome variables }^{1} \\
\text { Predictors }^{2}\end{array}$} & \multicolumn{2}{|c|}{ Survival entrepreneurship } & \multicolumn{2}{|c|}{ Entrepreneurial success } \\
\hline & $(1)$ & $(2)$ & $(3)$ & (4) \\
\hline \multicolumn{5}{|l|}{ Inputs } \\
\hline log (capital input) & $-.308 * * *$ & $-.314 * * *$ & .102 & .145 \\
\hline log (labour monthly input) & -.154 & -.158 & $.366 * * *$ & $.426 * * *$ \\
\hline \multicolumn{5}{|l|}{ Business characteristics } \\
\hline Production & -.041 & -.060 & .038 & .072 \\
\hline Retail trade & -.131 & -.102 & $.543 * * *$ & $.503 * * *$ \\
\hline Catering & -.185 & -.192 & $.577 * * *$ & $.651 * * *$ \\
\hline Pluriactivity & $-.162 *$ & -.155 & .058 & .029 \\
\hline Favourable economic situation ${ }^{2}$ & $-.169 *$ & $-.179 *$ & $.209 * *$ & $.218^{* *}$ \\
\hline \multicolumn{5}{|l|}{ Entrepreneur characteristics ${ }^{3}$} \\
\hline Ethnic group & -.033 & -.023 & .021 & -.064 \\
\hline Gender & -.052 & -.055 & .014 & .012 \\
\hline Primary education or more & -.022 & -.028 & .088 & .154 \\
\hline Experience & -.110 & -.138 & .036 & .068 \\
\hline Entrepreneurial behaviour score ${ }^{4}$ & $-.187^{*}$ & $-.229 * *$ & .170 & $.278^{* *}$ \\
\hline \multicolumn{5}{|l|}{ Network configuration $^{5}$} \\
\hline Urban Solidarity Network & - & $-.212^{* *}$ & - & $.358 * *$ \\
\hline Community Solidarity Network & - & -.046 & - & -.011 \\
\hline Linking Network & - & -.121 & - & -.070 \\
\hline Horizontal Business Network & - & $-.276 * * *$ & - & $.456 * * *$ \\
\hline-2 log likelihood & 289.928 & 282.740 & 198.933 & 181.207 \\
\hline Pseudo- $\mathrm{R}^{2}$ McFadden & .138 & .159 & .264 & .329 \\
\hline Akaike IC & 315.928 & 316.740 & 224.933 & 215.207 \\
\hline Bayesian IC & 362.708 & 377.913 & 271.712 & 276.381 \\
\hline
\end{tabular}

Notes : (1) dummy variables: survival entrepreneurship = 1 if entrepreneurs' primary income is less than $60 \%$ of median primary income, entrepreneurial success $=1$ if entrepreneur belongs to the highest quintile of primary income's distribution; (2) Standardized estimated coefficients are shown, *** $p<.01, * * p<.05, * p<$ .1 ; (2) this dummy variable distinguishes activities that experienced a favourable economic situation during past year; (3) dummy variables respectively distinguishing Mossi, female, most educated and most experienced (more than five years in present activity) entrepreneurs; (4) this score combinates six dummy variables (simplified book keeping, bank account holding, administrative registration of activity, belonging to a professional organization, entrepreneurship technical training and demand anticipation) and is weighted by each item frequency so that a relatively rare item weighs more than a more frequent one; (5) excluded value is "indistinct network, we simultaneously introduce the four dummies describing networks in the regressions as the separate introduction of each of them leads to similar conclusions. 
Table A.6. Means and standard deviations for predicted and predictor variables

\begin{tabular}{lcc}
\hline Variables & Mean & S. D. \\
\hline Log (monthly sales turnover) & 5.298 & .504 \\
Log (monthly primary income) & 4.649 & .504 \\
Log (capital input) & 5.268 & .740 \\
Log (labour monthly input) & 3.997 & .676 \\
Production & .348 & .477 \\
Retail trade & .300 & .459 \\
Catering & .122 & .328 \\
Pluriactivity & .130 & .337 \\
Favourable economic situation & .318 & .467 \\
Ethnic group (Mossi) & .369 & .490 \\
Gender (female) & .159 & .367 \\
Primary education or more & 648 & .478 \\
Experience (conducting this & .537 & .499 \\
Entrepreneurial behaviour score & 5.997 & 6.387 \\
\hline
\end{tabular}




\section{References}

Adams, A.M., Madhavan, S. and Simon, D. (2006). "Measuring social networks cross culturally". Social Networks, 28(4), 363-376.

Baland, J.-M., Guirkinger, C. and Mali, C. (2007). "Pretending to be Poor: Borrowing to Escape Forced Solidarity in Cameroon". Economic Development and Cultural Change, 60(1), 1-16.

Barr, A.M. (2002). "The Functional Diversity and Spillover Effects of Social Capital". Journal of African Economies, 11(1), 90-113.

Benjamin N., and Mbaye A. A. (2012), The Informal Sector in Francophone Africa: Firm Size, Productivity, and Institutions. Africa Development Forum - World Bank.

Berrou, J.-P. and Combarnous, F. (2011). "Testing Lin's Social Capital Theory in an Informal African Urban Economy". Journal of Development Studies, 47(8), 1216-1240.

Berrou, J.-P. and Combarnous, F. (2012). "The Personal Networks of Entrepreneurs in an Informal African Urban Economy: Does the "strength of ties" matter? Review of Social Economy, LXX (1), 1-30

Böhme M.-H. and Thiele, R. (2014). "Informal-Formal Linkages and Informal Enterprise Performance in Urban West Africa". The European Journal of Development Research, 26(4), 473-489.

Borgatti, S.P., Everett, M.G. and Freeman, L.C. (2002). UCINET 6 for Windows: User's Guide. Harvard: Analytic Technologies.

Burt, R. (1992). Structural Holes. The Social Structure of Competition. Harvard: Harvard University Press.

Campbell, K. and Lee, B (1991). "Name Generators in Surveys of Personal Networks". Social Networks, 13(3), 203-221.

Chen, M.A. (2014). "Informal Employment and Development: Patterns of inclusion and exclusion". European Journal of Development Research, 26(4), 397-418.

Coleman, J. (1988). "Social Capital in the Creation of Human Capital". American Journal of Sociology, 94, 95-120. 
Crossley, N., Bellotti, E., Edwards, G., Everett, M.G., Koskinen, J. and Tranmer, M. (2015). Social Network Analysis for Ego-Nets. London: SAGE Publications.

De Vreyer, P. and Roubaud, F. (eds) (2013). Urban Labor Markets in Sub-Saharan Africa, Africa Development Forum. Washington DC, World Bank.

Di Falco, S. and Bulte, E. (2011). "A Dark Side of Social Capital: Kinship, consumption, and savings". Journal of Development Studies, 47(8), 1128-1151.

Fafchamps, M. (2004). Market Institutions in Sub-Saharan Africa: Theory and Evidence. Massachusetts: MIT Press.

Fafchamps, M., McKenzie, D., Quinn, S. and Woodruff, C. (2014). "Microenterprise Growth and the Flypaper Effect: Evidence from a randomized experiment in Ghana". Journal of Development Economics, 106, 211-226

Fafchamps, M. and Minten, B. (2002). "Returns to Social Network Capital Among Traders". Oxford Economic Papers, 54, 173-206.

Fafchamps, M. and Quinn, S. (2016). "Networks and Manufacturing Firms in Africa: Results from a Randomized Field Experiment". CSAE Working Paper Series, 2014-25.

Fafchamps, M. and Woodruff C. (2016). "Identifying Gazelles: Expert panels vs. surveys as means to identify firms with rapid growth potential". Policy Research working paper, no. WPS 7647. Washington, D.C.: World Bank Group.

Fauré, Y.A. and Labazée, P. (2002). Socio-économie des villes africaines. Bobo et Korhogo dans les défis de la décentralisation. Paris: Karthala.

Fisher, C.S. (1982). To Dwell Among friends. Personal Networks in Town and City. Chicago: Chicago University Press.

Granovetter, M. (1973). "The Strength of Weak Ties". American Journal of Sociology, 78, 1360-1380.

Granovetter, M. (1983). "The Strength of Weak Ties: A network theory revisited". Sociological Theory, 1, 201-233. 
Granovetter, M. (1985). "Economic Action and Social Structure: The problem of embeddedness". American Journal of Sociology, 91 (3), 481-510.

Grimm, M., Gubert, F., Koriko, O., Lay, Y. and Nordman, C.J. (2013). "Kinship-ties and Entrepreneurship in Western African". Journal of Small Business and Entrepreneurship, 26(2), 125150.

Grimm, M., Hartwig, R. \& Lay, J. (2016). "Does Forced Solidarity Hamper Investment in Small and Micro-Enterprises ?". Journal of Comparative Economics (in press)

Grimm, M., Knorringa, P., \& Lay, J. (2012). "Constrained Gazelles: High potentials in West Africa’s informal economy". World Development, 40(7), 1352-1368.

Hoang, H. and Antoncic, B. (2003). "Network-Based Research in Entrepreneurship: A critical review". Journal of Business Venturing, 18(2), 165-187.

ILO (1993). Resolution concerning statistics of employment in the informal sector. Fifteenth International Conference of Labour Statisticians, Geneva, 1 January 1993.

Khayesi, J.N.O., Gerard, G. and John A. (2014). "Kinship in Entrepreneur Networks: Performance Effects of Resource Assembly in Africa". Entrepreneurship Theory and Practice, 38(6), 1323-1342.

Knorringa, P. and van Staveren, I. (2006). Social Capital for Industrial Development: Operationalizing the concept, Vienna: UNIDO - COMPID.

La Porta R. and Shleifer A. (2014). "Informality and Development", Journal of Economic Perspectives, 28(3), 109-126.

Lin, N. (2001). Social Capital: A Theory of Social Structure and Action. New York: Cambridge University Press.

Lourenço-Lindell, I. (2002). Walking the Tight Rope: Informal Livelihoods and Social Networks in a West African City. Stockholm : Almquist and Wiksell International.

Meagher, K. (2010). Identity Economics. Social Networks and the Informal Economy in Nigeria. Woodbridge: James Currey. 
Nordman, C. J. and Pasquier-Doumer, L. (2015). "Transitions in a West African Labour Market: The role of family networks". Journal of Behavioral and Experimental Economics, 54:74-85.

Slotte-Kock, S. and Coviello, N. (2010). "Entrepreneurship Research on Network Processes: A review and ways forward". Entrepreneurship: Theory and Practice, 34(1), 31-57.

Uzzi, B. (1997). "Social Structure and Competition in Interfirm Networks: The paradox of embeddedness". Administrative Science Quarterly, 42(1), 35-67.

Vanek J., Chen M., Carré F., Heintz J. and Hussmans R. (2014). "Statistics on the Informal Economy: Definitions, Regional Estimates and Challenges", WIEGO Working Paper (Statistics) No 2 - April 2014 Wellman, B. (2007). "Challenges in Collecting Personal Network Data: The nature of personal network analysis". Field Methods, 19, 111-115.

Werthmann, K. and Sanogo, M.L. (2013), La ville de Bobo-Dioulasso au Burkina Faso: urbanité et appartenances en Afrique de l'Ouest. Paris : Karthala.

Woolcock, M. (2001). "The Place of Social Capital in Understanding Social and Economic Outcomes". Canadian Journal of Policy Research, 2(1), 11-17.

World Bank (2009). World Development Report 2009. Reshaping Economic Geography. The World Bank, Washington DC. 


\section{Notes}

${ }^{1}$ The strength of a tie is defined by Granovetter (1973: 1361) as "a (probably linear) combination of the amount of time, the emotional intensity, the intimacy (mutual confiding), and the reciprocal services which characterize the tie."

${ }^{2}$ This two-step survey has some advantages (accumulation of trust with the respondent), but it also inevitably produces some attrition (abandon of respondents, problems of addresses...). Among the 278 cases, there are 8 cases for which data for economic outcomes are missing or unreliable. The statistical difference in quota sampling by localization and sector activity between the initial representative collected sample $(n=317)$ and our study sample $(\mathrm{n}=270)$ is not significant. Thus, there is no evidence of attrition issues in our study.

${ }^{3}$ A consequence of this method is that we don't define a priori nor exclude a priori specific social categories (as family ties for example). The network social composition is the consequence of the nature of the network that we observe, the network of support of an entrepreneur for his business. In this sense, our entrepreneurs' networks measures are quite distinct from family networks measures of Nordman and Pasquier-Doumer (2015) or Grimm et al. (2013).

${ }^{4}$ Statistical information about how respondents use their full allocation of three (or two) potential names for each generator is provided in Table A.1. No respondent used the total potential of 23 names among all generators (on average, respondents only used 30 per cent of the total potential). For each generator, very few of the respondents quoted the three potential names. These results suggest that limiting the generators to three names does not prevent from providing a reliable estimation of network size or degree and, more importantly, it does not prevent from perceiving the differences between the sizes of entrepreneurs' networks.

${ }^{5}$ The subsample is composed of the first quoted names for each generator, as proposed by Fischer (1982) in his survey of personal network support in San Francisco. Note that this subsample is not statistically different from the entire list of names (chi-square test for expected values of the distribution of the only characteristic observed in all network alters i.e. social role).

${ }^{6}$ Among all resources potentially conveyed by social relations, tangible resources include suppliers, customers, cooperation ties and financial and start-up support as opposed to advice and information, administrative support and recruitment ties (informational resources) 
${ }^{7}$ Therefore, alters with a lower status than the ego include informal employees and apprentices, small farmers and the non-working population, while those enjoying a comparable status include small-scale entrepreneurs and regular employees within the informal sector.

${ }^{8}$ Ties are considered heterophilic when alters are similar to egos for at most one of the four characteristics.

${ }^{9}$ For further details, see Burt (1992:54-56).

${ }^{10}$ The main features of our sample (activities' and entrepreneurs' characteristics) are described in Table A.2.

${ }^{11}$ The mixed classification procedure first involves performing a hierarchical cluster analysis before consolidating the relevant partition through K-means iterations aimed at increasing inter-cluster variance while minimizing intracluster variance. The relevant number of clusters (in this case four) is derived from the analysis of the dendrogram and the analysis of the inter- to intra-cluster variance ratio and the impact of K-means consolidation on this ratio in the different possible clusterings. Note that the multiple component analysis performed prior to the classification showed very stable results confirmed by twenty-five bootstrap replications of the initial sample.

${ }^{12}$ In technical terms, this "indistinct network" included 20 per cent of the entrepreneurs whose position in the initial multi-dimensional scatter plot was the closest to the barycentre in terms of Euclidean distance.

${ }^{13}$ Note that for independent workers, the value of $\log$ (labour input), which should normally be - $\infty$, was arbitrarily set to 3.17 to maintain the continuity of the variable.

${ }^{14}$ The score is computed as an inversely proportional weighted sum so that the greater the number of acquired entrepreneurial behaviours and the rarer their acquisition, the higher the score.

15 These ties created before the start of the business exhibit significant distinct features compared to the other ties, and notably regarding the social role with the importance of kinship ties. This is an interesting aspect for the quality of our instruments. As recognized in the literature in economics, family ties can often be seen as largely exogenous as they and cannot be so easily freely changed (Nordman and Pasquier-Doumer, 2015)

${ }^{16}$ Conversely, the $C S N$ shows that significant social pressure does not appear to be useful for business performance.

17 This result is easily understandable since the $L N$ is well developed among restaurant owners whose access to affluent customers serves to promote sales. 